\title{
Differential Ion Mobility Spectroscopy: Non-InVasive Real-time Diagnostics and Therapy Control in Metabolic Diseases
}

\author{
A. Kikowatz ${ }^{1}$, G. Becher ${ }^{2}$, S. Dietze ${ }^{3}$, W. Steinhäusser ${ }^{4}$, E. Beck ${ }^{5}$ \\ ${ }^{1}$ Neptuntec, Grüne Aue 54, 12683 Berlin, Germany; ${ }^{2}$ Becherconsult GmbH, Fröbelweg 33, 16321 Bernau, Germany; ${ }^{3}$ Stefan Dietze, \\ Birkenwerderweg 39, 16515 Oranienburg, Germany; ${ }^{4}$ CardinalHealth 234 Germany GmbH, Leibnizstr. 7, 97204 Höchberg, Germany; \\ ${ }^{5}$ Praxis Dr. med. Ekkehard Beck, Otto-Nuschke-Str. 2, 15562 Rüdersdorf, Germany
}

\begin{abstract}
Background: Over the last few years, differential ion mobility spectroscopy (DMS) has become an important tool in medical research. There are attempts to find markers for specific diseases in exhaled air, using this technology as a non-invasive early diagnosis.

Objective: In the present research, exhaled air from 78 patients with known diagnosis and 39 control persons were tested with a DMS system from Sionex.

Results: Bronchial asthma showed a pattern of 6 characteristic points in a discriminant analysis. Patients with diagnosed hypertension showed a characteristic pattern with 4 points, hypothyroidism 2 points; increased LDL cholesterol 3 points, and type II diabetics treated with insulin 4 spots. No significant differences with respect to the control group were found in chronic obstructive pulmonary disease patients. The DMS pattern in the tested asthmatics showed a partial change depending on different medications used.

Conclusion: Differential ion mobility spectroscopy offers promise as a helpful diagnostic tool.
\end{abstract}

Key words: differential ion mobility spectroscopy (DMS), real-time diagnostics, non-invasive diagnostics

\section{INTRODUCTION}

Scientific research at the University of California in Irvine showed that breath analysis is an effective, non-invasive method to determine the blood glucose level. Using an analytical method, primarily developed to measure air contamination, researchers found markedly increased methyl nitrate concentrations in exhaled air from children with type 1 diabetes [1]. They then tested ten children with type 1 diabetes with high as well as declining blood glucose levels after administration of insulin. Exhaled air from these patients was tested for 100 different markers in the ppt-range (parts per trillion). It has been shown that the concentration of methyl nitrate in patients is 10 times higher than in those with the normal glucose concentration and correlated with the level of blood sugar. In follow-up studies, researchers plan to correlate hyperglycemia with other gases in exhaled air to establish a complete profile of exhaled markers in diabetes [1]. These studies seem a prelude to the develop- ment of a breath analyzer for diabetics to control their insulin usage.

Different metabolized products, e.g., from tumor cells, from thoracic diseases and from different bacteria, but also from changes in metabolism due to medication, lead to different detectable metabolites in exhaled air [2, 3]. Today, it is possible to find and measure markers in exhaled air for diabetes $[4,5]$, breast cancer [6], tuberculosis [7], and lung cancer [8,9]. The concentration of most markers is very low, so most diagnostic standard tests do not capture them.

Already in 1971, Pauling et al [10] described an investigation of exhaled air using gas chromatography (GC) and found 250 different substances. In today's literature, the most described technology to measure exhaled air is gas chromatography using different detectors, such as mass sensitive detectors (MSD) [11], photo-ionization detectors (PID), flame-ionization detectors (FID), and also ion traps [12]. In most cases, enrichment of the samples is required because the concentration of analytes is only a few parts per million (ppm) or even parts per billion (ppb), which is usually below the detection limit. Enrichment is usually done with chemical or adsorptive binding to specific adsorbent materials with acceptable technical effort. Cooling traps are also used to concentrate the sample; however the technical complexity is high.

Other methods to analyze breath are different forms of mass spectrometry, proton-transfer reaction mass spectrometry (PTR-MS), and the selected ion flow tube mass spectrometry (SIFT-MS). Both the methods are useful for on-line analysis, have detection limits in a lower ppb-range, and short detection times. Technology is similar in both methods [13]. In the SIFT-MS, ions are created in a microwave plasma ion source which is external to the flow tube. The ions are then extracted from the ion source, selected according to their mass-to-charge ratio using a quadruple mass filter, injected into a flowing carrier gas sampled by a downstream pinhole orifice, mass analyzed, and counted by a differentially-pumped quadruple mass spectrometer system $[14,15]$.

Differential mobility spectroscopy (DMS) is a newer technique. It is capable of detecting metabolites at very low concentrations. Ion mobility spectroscopy detects different substances such as aldehydes, halogens, poly-aromatic substances and nitric compounds 
[16]. DMS gained importance to detect explosive and toxic agents during the Irak war. Today's uses include environmental monitoring, detection of narcotic or explosive markers in airports, also in the forensic chemical and criminalistic labs. Also, the international space station uses a DMS to monitor the air [17].

\section{MATERIAL AND METHODS}

Detection of metabolites in exhaled air requires coupling a differential mass spectrometer with a multicapillary column to reach a pre-separation of the known 250 substances [10]. Furthermore, a heated molecular trap with activated charcoal is used to enrich the sample. Coupled differential mass spectrometers like this allow the identification and quantification of volatile metabolites in exhaled air down to concentrations in the ppb level within 5 min. A DMS from Sionex in Bedford was used for the present study. The principle is shown in Fig 1. Probe collection is by a pump drawing air into the system through a 3 -way valve and preconcentration trap. A second pump creates a constant flow of carrier gas through a molecular filter, a carbon filter, and the ionization chamber. In a second step, the column is loaded. The 3 -way valve changes its pathway to allow flow of the carrier gas through the concentration trap and the column. At the same time, the trap is heated to the desired temperature to allow a desorption of molecules of interest from the trap to the column. In a last step, the column is heated and molecules flow through the ionization chamber to the DMx sensor depending on their retention time.

After passing through the ${ }^{63} \mathrm{Ni}$ ionization chamber, the charged ions pass with the carried gas through a tunable electric field and land at a positive or negative electrode as shown in Fig 1. The generated electric signal is transmitted to a PC by an analog-digital converter.

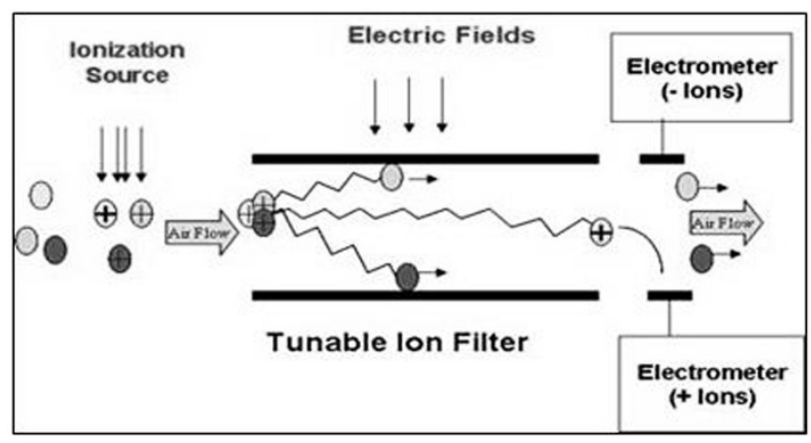

Fig. 1. Differential mass spectroscopy.

Different publications show the existence of various volatile organic compounds (VOC) in expired air at tracer levels. Breath consists of different groups of compounds. One consists of exogenous substances which must be taken into account with the measurement. These analytes are inspired from room air or picked up with food substances or even by dermal absorption of different fragrances or other active components, e.g., from sanitary products. They may be
Table 1. Questionnaire to access symptomatic and treatment details of volunteers.

\begin{tabular}{ll}
\hline 1 & Initials \\
2 & Gender \\
3 & Age \\
4 & Size \\
5 & Weight \\
6 & Time from last meal \\
7 & Nutrition \\
8 & Risk factors \\
9 & Diagnosis \\
10 & Other diseases \\
11 & Current lung disease \\
12 & Barometric pressure, temperature, humidity \\
\hline
\end{tabular}

transmitted to exhaled air by blood circulation [18]. Measurements with the DMS can be disturbed by such analytes in high concentration and may mask the wanted marker. For our research, we defined a useful test time after eating. Patients had to wait for $2 \mathrm{~h}$ after eating to be included into the study.

Our tests were conducted as a controlled, open-labeled monitoring study in 3 test centers in and around Berlin. Voluntary test persons with known diagnosis were selected, questioned, and measured. The patient questionnaire listed medication, eating habits, known diseases, and risk factors plus gender, size, weight, age, barometric pressure, temperature and humidity.

To prevent a direct patient's contact with the DMS, we used a special breathing tube, connected to the DMS by a teflon tube. The test procedure for the patient was a deep inspiration followed by a slow expiration through the sample tube. The internal pump collected $20 \mathrm{ml}$ out of the collection tube. The pump was started after expiration of the ventilatory dead space to make sure that only air from the central and lower airways was taken [19].

Analyzing time was 4 min and 30 s. Reference samples were collected from 39 healthy persons. Spectrums were compared and related to the questionnaire; a cluster analysis was carried out. A total of 117 participants were measured, 78 patients and 39 blank samples.

For the interpretation, discriminant analysis with previous cluster analysis was used, because the individual group association was known, and only differences between the groups were searched. Not only were the relations between variables studied, but the goal was to predict unknown values of dependant variables by means of declarative variables.

\section{RESUlTs AND Discussion}

Several patients showed different diseases at the same time. This resulted in the detection of 188 diseases in 117 patients. The result is shown in Fig. 2. Seventy eight patients included 17 smokers, 47 overweight (BMI >25), and 9 with adipositas (BMI >30); 23 male and 55 female patients participated in this pilot study. Among the 39 healthy subjects, there were 20 smokers, 16 overweight, none with heavy adipositas; 11 man 


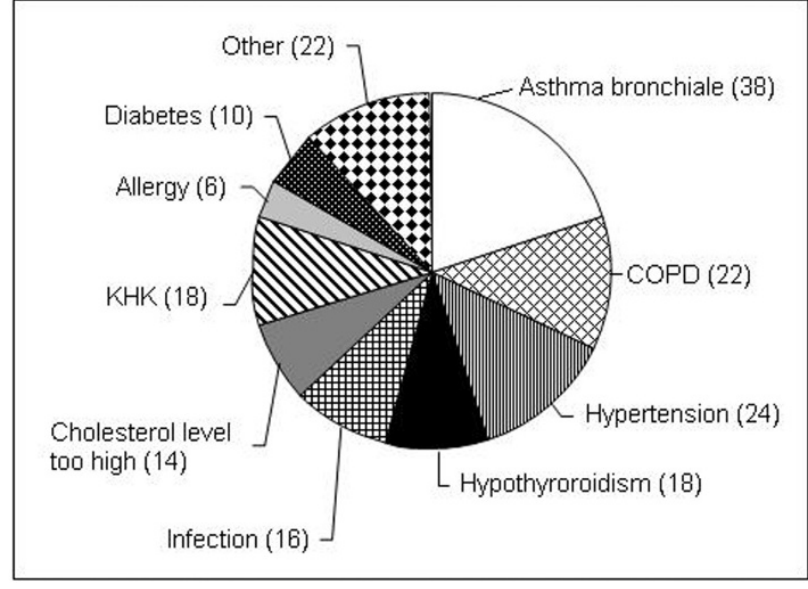

Fig. 2. Occurrence of different diseases in the tested population.

and 28 women. The mean age of patients was $59 \pm 14$ years; the reference group was $41 \pm 22$ years.

There was no age or weight dependant pattern in the discriminant analysis. Commonly, cholesterol is measured in the lab from blood. Cholesterol comes from food or from the liver which generates cholesterol. Increased cholesterol level itself is not a disease, but is an indicator for increased risk of arteriosclerosis. The cholesterol value also is of interest for increased risk of coronary cardiac disease and circulatory problems. Fourteen out of our 117 patients report- ed increased LDL cholesterol levels and took medication to lower their cholesterol. These patients showed matching patterns in the cluster analysis. Twenty one of the other tested subjects showed the same pattern. None of these were treated for high cholesterol, nor took any cholesterol lowering medication. This shows that the pattern really corresponded to the high cholesterol level rather than medication.

In healthy individuals, the thyroid gland delivers the hormones thyroxin and triiodothyronine into the blood. This requires iodine. The daily need for an adult is approximately $200 \mu \mathrm{g}$ per day. Sufficient uptake with food is not always warranted in countries like Germany [20]. Eighteen of our patients reported to be treated for thyroid hypofunction. They all showed a specific pattern which is shown in Fig. 3 (Group 2). Noticeably, 4 of the 18 patients also had increased LDL cholesterol which is known to go along with thyroid hypofunction.

No specific pattern was found in the COPD patients. Twenty two of these patients had diverse metabolites in their breath. Seven of the COPD patients reported to have coronary heart disease. They, plus another 11 patients with coronary heart disease, could be grouped into a total of 18 patients with established coronary disease as shown in Fig. 3 (Group 5). Six of them also showed thyroid hypofunction.

Chronic airway diseases, like bronchial asthma, are serious diseases with rising prevalence. The immune system and the nervous system are involved into the pathomechanisms of these diseases. Both systems in-

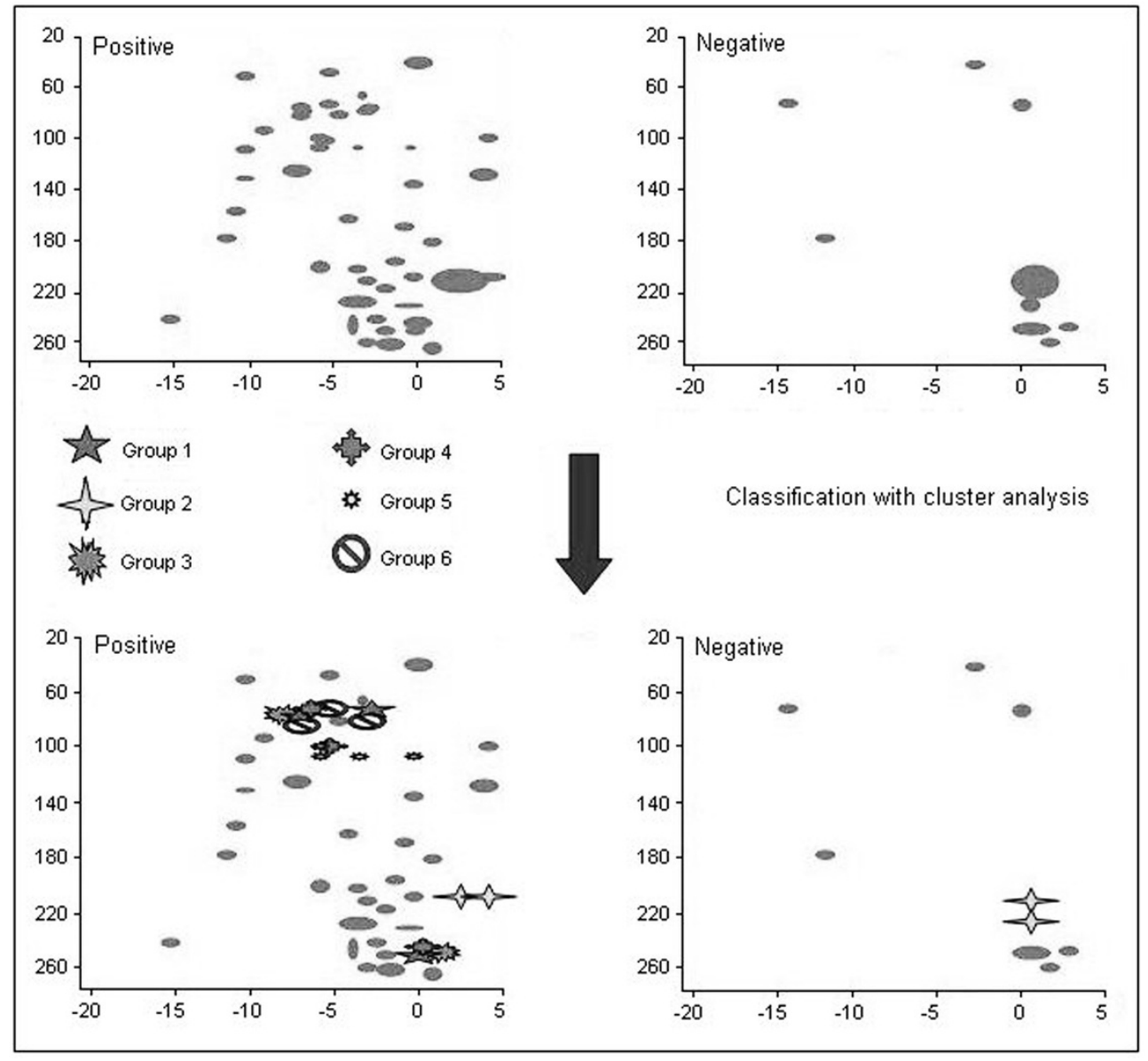

Fig. 3. Cluster analysis. The upper pictures show the positive and negative spectrums from one patient, without allocating the different points. The lower pictures show the same spectrum after allocating several points to groups using cluster analysis. 
teract through different mediators, some of which are the neutrophins. The four neutrophins BDNF, NGF, NT-3, and NT-4/5 play an important role in the activation and differentiation of immune cells and have additional influence on structural cells, like epithelium cells or fibroblasts/myofibroblasts. Asthmatics show an increased concentration of these neutrophins [21]. Our asthma patients showed an interesting fact: a total of 38 asthmatics had to be assigned to 3 different groups: Group 4, Group 6 (Fig. 3), and Group 7 (not shown in Fig. 3). A comparison of the patients' data showed a difference to be dependent on the individual's medication. Depending on the kind of medication, only 3 out of the 6 metabolites present in all asthmatic patients could be traced. No subject of the control group and no asthmatic patient, according to the questionnaire, could be related to Groups 4, 6, and 7.

VOCs found in connection with diabetes mellitus are described in publications by Amann and Smith [4] and Phillips et al [5]. A very noticeable pattern could be connected to diabetes type II patients. However, based on the high amount of non-detection of this pattern and concord with patients from Group 2 taking medications, it can be assumed that the medication is responsible for the pattern. The patients from Group 2 regularly take insulin.

During the study time, slight dislocation of the patterns occurred which were most likely created by changes in humidity and barometric pressure. The patterns were slightly offset proportionally. Because using the cluster and discriminant analyses only the patterns were detected, the absolute coordinates could be neglected.

\section{SUMMARY}

1/ The DMS technology is today widespread as a detection method for explosives, chemical weapons, and drugs. Space research uses the DMX to monitor the air in the space shuttle. An analysis of exhaled air is already studied in various places.

2/ Analysis of exhaled air is already commonplace for O2, CO2, NO, and other gases. The use of a DMS to analyze volatile organic compounds is underway and a user-friendly instrument is the next development goal.

3/ Our preliminary results with asthmatics, patients with hypothyreosis, hypertension, diabetes type II, and hypercholesterolemia show that the Sionex unit is useful for breath analysis. The use of this unit to monitor the effects of medication or for the early detection of a diseases, e.g., like lung carcinoma, is possible.

Acknowledgement: We would like to thank Dr. med. Ekkehard Beck in Rüdersdorf, Dr. med. Timm Labsch in Bernau, F. A. Carola Becher and bei Dr. med. Sören Schmidtmann in Berlin for making available their doctor's practice and for guiding the patients. Furthermore, we thank Cardinal Health (now Carefusion) for their support and all participants for their attendance.

Conflicts of interest: The authors declared no conflicts of interest in relation to this article.

\section{REFERENCES}

[1] Pauling L, Robinson AB, Teranishi R, Cary P (1971) Quantitative analysis of urine vapor and breath by gasliquid partition chromatography. Proc Nat Acad Sci USA 68(10): 2374-2376.

[2] Phillips M, Herrera J, Krishnan S, Zain M, Greenberg J, Cataneo RN (1999) Variation in volatile organic compounds in the breath of normal humans. J Chromatogr B $729(1-2): 75-88$.

[3] Yu H, Xu L, Wang P (2005) Solid phase microextraction for analysis of alkanes and aromatic hydrocarbons in human breath. J Chromatogr B 826: 69-74.

[4] Amann A, Smith D (2005) Breath Analysis for clinical diagnosis and therapeutic monitoring. World Scientific. Singapore.

[5] Phillips M, Cataneo RN, Cheema T, Greenberg J (2004) Increased breath biomarkers of oxidative stress in diabetes mellitus. Clin Chim Acta 344: 189-194.

[6] Phillips M, Cataneo RN, Ditkoff BA, Fisher P, Greenberg J, Gunawardena R, Kwon CS, Rahbari-Oskoui F, Wong C (2003) Volatile markers of breast cancer in the breath. Breast J 9(3): 184-191.

[7] Phillips M, Cataneo RN, Condos R, Ring Erickson GA, Greenberg J, La Bombardi V, Munawar MI, Tietje O (2006) Volatile biomarkers of pulmonary tuberculosis in the breath. Tuberculosis 87(1): 44-52.

[8] Phillips M, Glesson K, Hughes JMB, Greenberg J, Cataneo RN, Baker L, McVay WP (1999) Volatile organic compounds in breath as markers of lung cancer: a crosssectional study. Lancet 353: 1930-1933.

[9] Poli D, Carbognani P, Corradi M, Goldoni M, Acampa O, Balbi B, Bianchi L, Rusca M, Mutti A (2005) Exhaled volatile organic compounds in patients with non-small cell lung cancer: cross sectional and nested short-term follow-up study. Respir Res 6: 71-80.

[10] Pauling L, Robinson AB, Teranishi R, Cary P (1971) Quantitative analysis of urine vapor and breath by gasliquid partition chromatography. Proc Nat Acad Sci USA 68(10): 2374-2376.

[11] Brunnemann KD, Kagan MR, Cox JE, Hoffmann D (1989) Determination of benzene, toluene, and 1,3-butadiene in cigarette smoke by GC-MSD. Exp Pathol 37: 108-113.

[12] Snipes MB, Spoo JW, Brookins LK, Jones SE, Mauderly JL, Orwat TB, Stiver JH, Dahl AR (1991) A method for measuring nasal and lung uptake of inhaled vapour. Toxicol Sci 16: 81-91.

[13] Buszewski B, Kesy M, Ligor T, Amann A (2007) Human exhaled air analytics: biomarkers of diseases. Biomed Chromatogr 21(6): 553-566.

[14] Smith D, Spanel P (2001) On-line measurement of the absolute humidity of air, breath and liquid headspace samples by selected ion flow tube mass spectrometry. Rapid Commun Mass Spectrom 15: 563-569.

[15] Spanel P, Smith D (2007) Selected ion flow tube: a technique for quantitative trace gas. Herold G. Innere Medizin. Herold; Auflage 1.

[16] Roehl JE (1991) Environmental and process applications for ion mobility spectrometry. Appl Specrosc Rev 26(1-2): $1-57$.

[17] Keller T (2005) Ionenmobilitätsspektrometrie. Wissenschaftl. Verlag Berlin.

[18] Grundmann A (2005) Untersuchung zur Eignung von Atemluft als Diagnosematrix mittels Gaschromatographie in Kombination mit adsorptiver Anreicherung und massenspektrometrischer Detektion. Dissertiationsschrift http://hdl.handle.net/2003/21791.

[19] Kauczor HU, Markstaller K, Heussel CP (2002) Pulmonary structure and function. High-resolution and dynamic computed tomography in pulmonary emphysema and airway diseases. Pneumologie 56: 24-30. 
[20] Miehle K, Paschke R (2004) Sind TSH-Rezeptor Polymorphismen eine mögliche Ursache für die interindividuell unterschiedlichen Normalbereiche der TSH-, fT3- und fT4-Werte in einer Normalpopulation? In: Universität Leipzig, Forschungsbericht.

[21] Napierala J (2009) Effect of neurotrophins on proliferation, metabolism and differentiation of fibroblasts to myofibroblasts in pathogenesis of allergic bronchial asthma. Universität Marburg.
Author's address:

A. Kikowatz

Neptuntec

Grüne Aue 54

12683 Berlin

Germany

E-mail: kikowatz@neptuntec.de 